\title{
Heme Regulates Exocrine Peptidase Precursor Genes in Zebrafish
}

\author{
Han Wang, ${ }^{1}$ Qingchun Zhou, Jason W. Kesinger, Chad Norris, and Cammi Valdez \\ Department of Zoology and Stephenson Research \& Technology Center, University of Oklahoma, \\ Norman, Oklahoma 73019
}

\begin{abstract}
We previously determined that yquem harbors a mutation in the gene encoding uroporphyrinogen decarboxylase (UROD), the fifth enzyme in heme biosynthesis, and established zebrafish yquem $\left(y q e^{t p 61}\right)$ as a vertebrate model for human hepatoerythropoietic porphyria (HEP). Here we report that six exocrine peptidase precursor genes, carboxypeptidase $A$, trypsin precursor, trypsin like, chymotrypsinogen B1, chymotrypsinogen 1-like, and elastase 2 like, are downregulated in yquem/urod (-I - ), identified initially by microarray analysis of yquem/urod zebrafish and, subsequently, confirmed by in situ hybridization. We then determined downregulation of these six zymogens specifically in the exocrine pancreas of sauternes (sau ${ }^{t b 223}$ ) larvae, carrying a mutation in the gene encoding $\delta$-aminolevulinate synthase (ALAS2), the first enzyme in heme biosynthesis. We also found that ptf1a, a transcription factor regulating exocrine zymogens, is downregulated in both yquem/urod (-I-) and sau/alas2 (-I-) larvae. Further, hemin treatment rescues expression of ptf1a and these six zymogens in both yquem/urod $(-I-)$ and sauternes/alas2 (-I-) larvae. Thus, it appears that heme deficiency downregulates ptf1a, which, in turn, leads to downregulation of exocrine zymogens. Our findings provide a better understanding of heme deficiency pathogenesis and enhance our ability to diagnose and treat patients with porphyria or pancreatic diseases. Exp Biol Med 232:1170-1180, 2007
\end{abstract}

Key words: heme; zymogens; pancreas; porphyria; zebrafish

\section{Introduction}

Heme (ferroprotoporphyrin IX) is widely known to be the prosthetic group for a number of proteins and enzymes

The research was supported in part by grant 1P20RR17703-05 from the National Institutes of Health, grant 2002-12-103 from the Whitehall Foundation, and grant HR04-140S from the Oklahoma Health Research Program to H.W

${ }^{1}$ To whom correspondence should be addressed at Department of Zoology and Stephenson Research \& Technology Center, University of Oklahoma, Norman, OK 73019. E-mail: hwang@ou.edu

Received March 21, 2007.

Accepted June 18, 2007.

DOI: $10.3181 / 0703-\mathrm{RM}-77$

$1535-3702 / 07 / 2329-1170 \$ 15.00$

Copyright (C) 2007 by the Society for Experimental Biology and Medicine that play critical roles in oxygen delivery and mitochondrial function, such as hemoglobin, catalases, and cytochromes. Heme also serves as a signaling molecule that controls numerous molecular and cellular processes (1). For instance, heme is essential for differentiation of mammalian erythroid, hepatic and nervous cells (2-5) and also suppresses the apoptosis of human neutrophils (6), PC12 neurons (7), and HeLa cells (8).

Heme biosynthesis is catalyzed by a cascade of eight enzymatic reactions, which is highly conserved from bacteria to mammals. Defective enzymatic activities of these enzymes result in heme deficiency and human anemia or porphyrias $(1,4)$. Four mutants with deficient enzymes in heme biosynthesis, $\delta$-aminolevulinate synthase (ALAS2), $\delta$ aminolevulinic acid dehydratase (ALAD), uroporphyrinogen decarboxylase (UROD), and ferrochelatase (FCH), have been studied in zebrafish and medaka fish (9-12). These mutants all exhibit heme deficiencies resulting from their defective enzymes in the heme biosynthetic pathway (9-12). Zebrafish sauternes $\left(\mathrm{sau}^{\text {tb223 }}\right)$ was modeled for human congenital siderbalstic anemia (CSA; Online Mendelian Inheritance in Man [OMIM] 301300, John Hopkins University, Baltimore, MD) because of its microcytic and hypochromic phenotype, derived from a missense mutation (V249D) in the gene encoding, the first and rate-liming erythroid-specific $\delta$ isoform of ALAS2 (EC 2.3.1.375) in the heme biosynthetic pathway (10). Medaka whiteout (who) is reminiscent of human ALAD porphyria (ADP; OMIM 125270) because of a missense mutation (L251Q) in the gene encoding $\delta$ aminolevuninic acid dehydratase (ALAD; EC 4.2.1.24), the second enzyme in the pathway. Zebrafish yquem $\left(y q e^{t p 61}\right)$ was established as a vertebrate model for human hepatoerythropoietic porphyria (HEP; OMIM 176100) as a result of a missense mutation (M38R) in the gene encoding UROD (EC 4.1.1.37), the fifth enzyme in the pathway (9). Finally, zebrafish dracula $\left(\operatorname{dra}^{m 248}\right)$ represents an animal model of human erythropoietic protoporphyria (EPP; OMIM 177000) that resulted from a slice donor mutation in the gene encoding FCH (EC 4.99.1.1), the final enzyme in the pathway (11). These fish mutants are invaluable resources for elucidating molecular 
genetic mechanisms underlying human anemia and porphyria diseases $(9-12)$.

In this study, we performed microarray analysis of yquem/urod and wild-type control zebrafish and observed downregulation of six exocrine peptidase precursor genes, including carboxypeptidase A (cpa), trypsin precursor (try), trypsin like (tryl), chymotrypsinogen B1 (ctrbl), chymotrypsinogen 1-like (ctrll), and elastase 2 like (ela2l), in yquem/ urod (-1-). We then found downregulation of these six zymogens in zebrafish sauternes $\left(\operatorname{sau}^{t b 223}\right)$. We also determined downregulation of ptfla, a transcription factor regulating exocrine zymogens, in both yquem/urod (-/-) and sauternes/alas2 (-/-). Additionally, hemin treatment was able to restore expression of ptfla and these six zymogens in both yquem/urod (-/-) and sauternes/alas2 (-I-) larvae. Hence, heme deficiency appears to downregulate ptfla, which may result in downregulation of exocrine zymogens. These findings provide a better understanding of heme deficiency pathogenesis and enhance our ability to diagnose and treat patients with porphyria or pancreatic diseases.

\section{Materials and Methods}

Fish Husbandry and Embryo Production. All animal protocols were approved by the University of Oklahoma's Institutional Animal Care and Use Committee (IACUC). Zebrafish (Danio rerio), wild-type AB strain, and mutant lines yquem $\left(y q e^{t p 61}\right)(9)$ and sauternes $\left(\right.$ sau $^{t b 223}$ ) (10) are raised at our fish facility according to standard protocols (13). Wild-type (WT) and mutant larvae were produced by pair mating, collected for RNA isolation, and fixed for in situ hybridization experiments at specified stages. Homozygous mutants yquem/urod (-1-) were obtained by mating heterozygous fish (yquem, $+/-)$ and then identified under a microscope with UV light. Homozygous mutants sau/alas2 (-/-) were identified under a light microscope after crossing heterozygous fish (sauternes, +/-).

RNA Isolation. Total RNAs from approximately 50 of the homozygous yquem/urod and wild-type larvae were extracted using TRIZOL (Invitrogen, Carlsbad, CA) at 56, 72,84 , and 96 hrs postfertilization (hpf). RNA quality was analyzed by capillary gel electrophoresis with an Agilent Bioanalyzer 2100 (Agilent Technologies, Santa Clara, CA), and RNA quantity was measured by a UV spectrophotometer. One zebrafish larvae pool was used for each stage of the mutant and WT control larvae examined.

Oligonucleotide Array Production. A zebrafish oligonucleotide library containing gene-specific 50-mer oligonucleotides representing approximately 14,067 transcripts was used. The library was originally generated by MWG Biotech and is now owned by Ocimum Biosolutions (Indianapolis, IN). The oligonucleotide probes were spotted onto Corning UltraGAPS amino-silane coated slides (Corning, Acton, MA) and covalently fixed to the surface of the glass using UV radiation in a UV Stratalinker model 1800
(Stratagene, La Jolla, CA). The printed slides then were blocked with succinic anhydride/sodium borate solution (Sigma, St. Louis, MO).

cDNA Labeling. cDNA was labeled with direct incorporation of Cy3-dUTP (Amersham Biosciences, Piscataway, NJ) from $2 \mu \mathrm{g}$ of total RNA using Qiagen OmniScript reverse transcriptase (Qiagen). RNA was mixed with $500 \mathrm{ng}$ of anchored oligo-dT primer, brought to $13.5 \mu \mathrm{l}$ volume with diethypyrocarbonate water and heated to $65^{\circ} \mathrm{C}$ for 5 mins. Then, this RNA and oligo-dT primer mix was added to $6.5 \mu \mathrm{l}$ solution containing $2 \mu \mathrm{l}$ of $10 \times$ OmniScript RT buffer (Qiagen), 0.5 nmole Cy3-deoxyuridine triphosphate (dUTP), $2.5 \mathrm{~m} M$ each of deoxyadenosine triphosphate (dATP), deoxycytidine triphosphate (dCTP), and deoxyguanosine triphosphate (dGTP), $1.5 \mathrm{~m} M$ TTP, 40 units of ribonuclease (RNase) inhibitor, and $4 \mathrm{U}$ OmniScript reverse transcriptase (Qiagen). The labeling reactions were performed at $37^{\circ} \mathrm{C}$ for $2 \mathrm{hrs}$ using a Gene Amp PCR System 9700 (Perkin-Elmer Applied Biosystems, Foster City, CA) and terminated by adding $2 \mu \mathrm{l}$ of $2.5 \mathrm{~N}$ sodium hydroxide $(\mathrm{NaOH})$ and incubating at $37^{\circ} \mathrm{C}$ for 15 mins. The final cDNA solution was neutralized with $10 \mu \mathrm{l}$ of $2 M$ HEPES. cDNA was purified with a Montage 96-well format vacuum system (Millipore, Billerica, MA).

Hybridization and Data Acquisition. The purified Cy3-labeled cDNA was then mixed with ChipHybe hybridization buffer (Ventana Medical Systems, Tucson, AZ) containing Cot-1 DNA $(0.5 \mathrm{mg} / \mathrm{ml})$, yeast tRNA $(0.2 \mathrm{mg} /$ $\mathrm{ml})$, and poly $(\mathrm{dA})_{40-60}(0.4 \mathrm{mg} / \mathrm{ml})$. Hybridization was conducted on a Ventana Discovery system for $9 \mathrm{hrs}$ at $58^{\circ} \mathrm{C}$. Each labeled cDNA was hybridized to a separate array. Hybridized microarrays were washed and then scanned at $5 \mu \mathrm{m}$ resolution with an Agilent fluorescent scanner (Agilent Technologies, Santa Clara, CA). Fluorescent intensity was measured and analyzed by Imagene software (BioDiscovery, El Segundo, CA).

Normalization of Microarray Data. Microarray data normalization was conducted as previously described (14). Briefly, the procedure assumes fluorescent signals from genes not expressed by the larvae are normally distributed, and these fluorescent signal values were used to calculate their mean $\left(\mathrm{S}_{0}\right)$ and standard deviation $\left(\mathrm{SD}_{0}\right)$ using an iterative, nonlinear curve-fitting procedure. Genes significantly expressed above background $(>3$ SD above background) were selected for further normalization, and their gene expression values were log-transformed with substitution of negative values by the lowest positive logarithmic value. Adjustment of the expression profiles of those genes that were significantly expressed above background to each other was conducted using a robust regression procedure (14). In addition, the raw microarray data of this study were deposited into Gene Expression Omnibus (GEO; http://www.ncbi.nlm.nih.gov/projects/geo/; accession GSE8651).

Determination of Differentially Expressed Genes. To determine differentially expressed genes, both 
Table 1. Exocrine Peptidase Precursor Genes Downregulated In yqe/urod Revealed By Microarray Analysis ${ }^{a}$

\begin{tabular}{|c|c|c|c|c|c|c|c|c|}
\hline \multirow{2}{*}{$\begin{array}{l}\text { Gene } \\
\text { chip ID }\end{array}$} & \multirow{2}{*}{$\begin{array}{l}\text { Gene } \\
\text { name }\end{array}$} & \multirow{2}{*}{$\begin{array}{c}\text { Genbank } \\
\text { accession }\end{array}$} & \multirow[b]{2}{*}{$\mathrm{Pa}^{b}$} & \multicolumn{3}{|c|}{ Ratio of WT/yqe ${ }^{c}$} & \multirow[b]{2}{*}{ Function } & \multirow{2}{*}{$\begin{array}{c}\text { Chromosomal } \\
\text { location }\end{array}$} \\
\hline & & & & $72 \mathrm{hpf}$ & $84 \mathrm{hpf}$ & $96 \mathrm{hpf}$ & & \\
\hline \#07482 & cpa & AF376130 & 0.04 & 1.11 & 2.70 & 4.40 & carboxypeptidase A activity & 25 \\
\hline \#04804 & try & AJ297822 & 0.009 & 1.43 & 3.12 & 4.69 & chymotrypsin activity & 17 \\
\hline \#01831 & tryl & ВC055625 & 0.05 & 3.21 & 19.77 & 12.98 & trypsin activity & 16 \\
\hline \#09049 & ctrb1 & ВC055574 & 0.02 & 1.63 & 4.68 & 11.34 & chymotrypsin activity & 7 \\
\hline \#01114 & ctr1I & NM_001004582 & 0.002 & 1.04 & 9.00 & 2.21 & chymotrypsin activity & 15 \\
\hline \#06255 & ela2l & AY179345 & 0.007 & 1.25 & 0.92 & 2.39 & chymotrypsin activity & 20 \\
\hline
\end{tabular}

${ }^{a}$ Microarray analysis was performed following the procedures as described (see Materials and Methods). Among more than 14,000 genes examined, 14 downregulated genes and 12 upregulated genes were revealed in yqe/urod larvae by microarray analysis (Supplemental Tables 1 and 2, available online). Six downregulated exocrine peptidase precursor genes are listed in the table. BLAST and phylogenetic analyses were used to annotate all the six genes (see Materials and Methods). Gene names and putative functions are from ZFIN (http://zfin.org/cgi-bin/ webdriver?Mlval=aa-ZDB_home.apg). The genomic locations of these genes are from ensembl (http://www.ensembl.org/Danio_rerio/ index.html). The raw microarray data was submitted into Gene Expression Omnibus (GEO; http://www.ncbi.nlm.nih.gov/projects/geo/; GEO accession GSE8651).

${ }^{b} \mathrm{~Pa}$, the probability for Associative $T$ test. Genes with $\mathrm{Pa}<0.05$ are potentially differentially expressed.

${ }^{c}$ At least 2-fold ratio of WT to yqe, i.e., reduced expression in yqe/urod (-I-) relative to WT controls in at least two of 72,84 , and $96 \mathrm{hpf}$, except for ela2l, which only has 2 -fold mutant reduction at $96 \mathrm{hpf}$.

Student's $t$ test and Associative $T$ test were computed with the normalized genes. The ratio of WT versus yqe/urod was also calculated for 56, 72, 84, and $96 \mathrm{hpf}$ developmental stages. Although genes selected by Student's $t$ test with $P<$ 0.05 alone are likely false positives for differential expression, genes selected by Associative $T$ test with $P<$ 0.05 alone are potentially real positives that require independent experimental confirmation (14). For our study, only genes with significant Associative $T$ test $(\mathrm{Pa}<0.05)$ and $\geq 2$-fold changes between WT and yqe/urod in at least two of the four developmental stages examined were selected as potential differentially expressed genes (Supplemental Tables 1 and 2, available in the online version of the journal).

Annotation, Sequence Alignment, and Phylogenetic Analysis. We used the Ocimum sequences to Basic Local Alignment Search Tool (BLAST) against NCBI (http://www.ncbi.nlm.nih.gov/BLAST/) and ensembl (http://www.ensembl.org/) databases to obtain full-length cDNA sequences and genomic locations, when available. The full-length cDNA sequences were re-BLASTed against the NCBI database to ascertain their identities. For these peptidase precursor genes, except for $c p a$, homologous and orthologous sequences of the genes from Takifugu rubripes, Tetraodon nigroviridis, Homo sapiens, Rattus norvegicus, Mus musculus, and two bacteria,

Methanosarcina barkeri and Bdellovibrio bacteriovorus HD100, were also obtained. Multiple sequence alignments were generated using ClustalX (15) and viewed with BioEdit (16). Phylogenetic analyses were then performed using amino acid alignments with the neighbor-joining method (1000 bootstraps) by MEGA 3.1 (17). Genbank accession numbers of proteins used are listed in the online Supplemental Table 3.

Generation of RNA Probes. DNA templates for generating RNA probes were first amplified from zebrafish larval RNAs by reverse transcriptase-polymerase chain reaction (RT-PCR) via RT-PCR Access (Promega, Madison, WI), with a thermal profile of one cycle of $48^{\circ} \mathrm{C}$ for 45 mins; one cycle of $94^{\circ} \mathrm{C}$ for 2 mins; 40 cycles of $94^{\circ} \mathrm{C}$ for 30 secs, $55^{\circ} \mathrm{C}$ for $30 \mathrm{secs}$, and $68^{\circ} \mathrm{C}$ for $60 \mathrm{secs}$; and one cycle of $68^{\circ} \mathrm{C}$ for 10 mins. Primers for the genes examined were designed to cover the partial coding regions and $3^{\prime}$ untranslated regions (UTRs) to increase specificity (See Table 2). The RT-PCR products were then subcloned into the pCR4-TOPO vector (Invitrogen). The positive clones identified by colony polymerase chain reaction (PCR) were subsequently sequenced to ascertain the identities and orientations of the genes in the vector. RNA probes were labeled with digoxigenin (DIG) using a RNA labeling kit (Roche, Indianapolis, IN).

Whole-Mount In Situ Hybridization. Wholemount in situ hybridization was conducted as previously described (13). Briefly, fixed larvae were incubated in 50\% formamide hybridization buffer with a DIG-labeled RNA probe at $70^{\circ} \mathrm{C}$ for $18-20$ hrs. Both nitro blue tetrazolium (NBT) and 5-bromo-4-chloro-3-indolyl phosphate (BCIP; Roche) were used for colorimetric detection. For each in situ hybridization, 10-15 larvae were used. At least three independent in situ hybridization experiments were conducted for each gene with an antisense probe, and at least one was conducted for each gene with a sense probe as control (not shown).

In Situ Hybridization Imaging Acquisition and Analysis. Following whole-mount in situ hybridization, larvae were placed in $4 \%$ methyl cellulose and observed under a dissecting stereoscope. The in situ hybridization images were acquired with a Leica MZ FLIII stereomicroscope and a Magnafire-cooled charge-coupled device camera and processed with Image Pro Plus (MediaCybernetics, Bethesda, MD), NIH ImageJ (http://rsb.info.nih.gov/ ij/, National Institutes of Health, Bethesda, MD), and Adobe (San Jose, CA) Photoshop. Identical microscopic and camera settings were used for each experiment. The optical 
Table 2. Primer Sequences for RT-PCR Amplification ${ }^{a}$

\begin{tabular}{|c|c|}
\hline Gene name & Primer sequence \\
\hline сра & $\begin{array}{l}\text { ZF151FOR, 5'-TCGTCTACACCCACACCAAA-3' } \\
\text { ZF151REV, 5'-CTTTCCGTCTGAAATGTTGCT-3' }\end{array}$ \\
\hline try & $\begin{array}{l}\text { ZF111FOR, 5'-TACAACAGCAACACCCTGGA-3' } \\
\text { ZF111REV, 5'-TGCTTTGCCAGATGGTATTG-3' }\end{array}$ \\
\hline tryl & $\begin{array}{l}\text { ZF117FOR, 5'-GTTTGGGCGAACACAACATC-3' } \\
\text { ZF117REV, } \text { 5'-TTCACAAGTGTTATCTCCAAAACAA-3' }^{\prime}\end{array}$ \\
\hline ctrb1 & $\begin{array}{l}\text { ZF118FOR, 5'-CCTTCTTTGGTGCAGCCTAT-3' } \\
\text { ZF118RFV, 5'-ATGACAGGATTCATTGCTGCT-3' }\end{array}$ \\
\hline ctr1I & $\begin{array}{l}\text { ZF 155FOR', 5'-TGGATCCCTGATCAACCAGT-3' } \\
\text { ZF155REV', 5'-TTTTATTGGCATTTTCTTCAGAGAG-3' }\end{array}$ \\
\hline ela2l & $\begin{array}{l}\text { ZF152FOR, 5'-ACTTGCGGTGGAAGCCTTAT-3' } \\
\text { ZF152REV', 5'-AAGGCATCGATGATACAAATCC-3' }\end{array}$ \\
\hline ptf1a & $\begin{array}{l}\text { ZF179FOR, 5'-GAGGGACTGCGATCTCACAT-3' } \\
\text { ZF179REV', 5'-GGCTGAAACACAGATAGTCACAA-3' }\end{array}$ \\
\hline
\end{tabular}

${ }^{a}$ To generate RNA probes, we amplified DNA fragments via RT-PCR for these seven genes (see Materials and Methods). The primer sequences are listed in the table.

density (O.D.) for the area stained $(S)$ and the neighboring background $(B)$ were measured using ImageJ software. The staining O.D. $=S-B$. Differences in signal intensities between treatments were analyzed by analysis of variance (ANOVA) or $t$ test. Results are expressed as mean optical density \pm standard error (SE).

Hemin Treatment. Hemin solution was prepared as previously described (18). Hemin (Sigma) was dissolved in $0.2 \mathrm{ml}$ of $1 \mathrm{~N} \mathrm{NaOH}$, then $1 \mathrm{ml}$ of $0.2 \mathrm{M}$ Tris- $\mathrm{HCl}(\mathrm{pH} 8)$, distilled, and deionized water was added to yield the desired concentration. The $\mathrm{pH}$ was adjusted to 7.8 with $1 \mathrm{~N} \mathrm{HCl}$.

\section{Results}

Downregulation of Six Peptidase Precursor Genes in the Zebrafish yquem/urod Exocrine Pancreas. The six peptidase precursor genes, cpa, try, tryl, ctrbl, ctr1l, and ela2l, are downregulated in the zebrafish yquem/urod mutant as shown by microarray analysis of yquem/urod and the control zebrafish ( $\mathrm{Pa}<$ 0.05 ; see Table 1). Whole-mount in situ hybridization was performed to confirm that all six peptidase precursor genes have significantly reduced expression domains, specifically in the zebrafish yquem/urod pancreas $(P<0.05, t$ test: see
Fig. 1). Because the heme deficiency resulted from defective UROD in this fish mutant, we hypothesized that heme might be required for transcription of these digestive enzyme genes. We also examined expression of insulin, glucagon, and somatostatin in both yquem/urod and control larvae at $92 \mathrm{hpf}$. No significant differential expression for these three endocrine genes was observed in yquem/urod or the control larvae $(P>0.05, t$ test; see online Supplemental Fig. 1). Hence, heme appears to exert its effect on exocrine genes per se without affecting endocrine genes.

Carboxypeptidase A (EC 3.4.17.1), one of the six peptidases studied, belongs to the MEROPS (http://merops. sanger.ac.uk/) peptidase family M14 (Carboxypeptidase A, clan MC). It is an exo-peptidase and can remove all Cterminal amino acids with the exception of Arg, Lys, and Pro (19). The remaining five peptidases contain a trypsinlike serine protease (tryp_SPc) domain and belong to the serine peptidase chymotrypsin family S1 (chymotrypsin A, clan PA). Phylogenetic analysis using the tryp_SPc domains of peptidases (online Supplemental Fig. 2) showed that the serine peptidases of fishes and mammals form monophyletic groups, suggesting that these serine peptidase genes are highly conserved throughout evolution (Fig. 2). Fish try and

Table 3. The Number of E-Box (CANNTG) Within the -6000 nt Upstream of the Transcription Initiation Site of These Six Exocrine Peptidase Precursor Genes ${ }^{a}$

\begin{tabular}{cll}
\hline Gene name & Ensembl accession & \multicolumn{1}{c}{ 5'-predicted E-boxes (number) $^{\prime}$} \\
\hline cpa & ENSDARG00000021339 & CAGCTG (2)/CACCTG (1), CATGTTG (1) \\
try & ENSDARG00000042993 & CAGCTG (1), CACGTG (1) \\
tryl & ENSD1 & CAGCTG (5)/CACCTG (4), CATGTTG (3) \\
ctr1l & ENSDARG000000030390 & CAGCTG (2) \\
ela2l & ENSDARG00000053900 & CAGCTG (1)/CACCTG (2) \\
ptf1a & ENSDARG00000041954 & CAGCTG (1), CACGTG (2) \\
\hline
\end{tabular}

${ }^{a}$ The genomic sequences of the seven genes were downloaded from ensembl (http://www.ensembl.org/Danio_rerio/index.html). The putative E-box sequences were searched manually for each gene and listed in the table. 

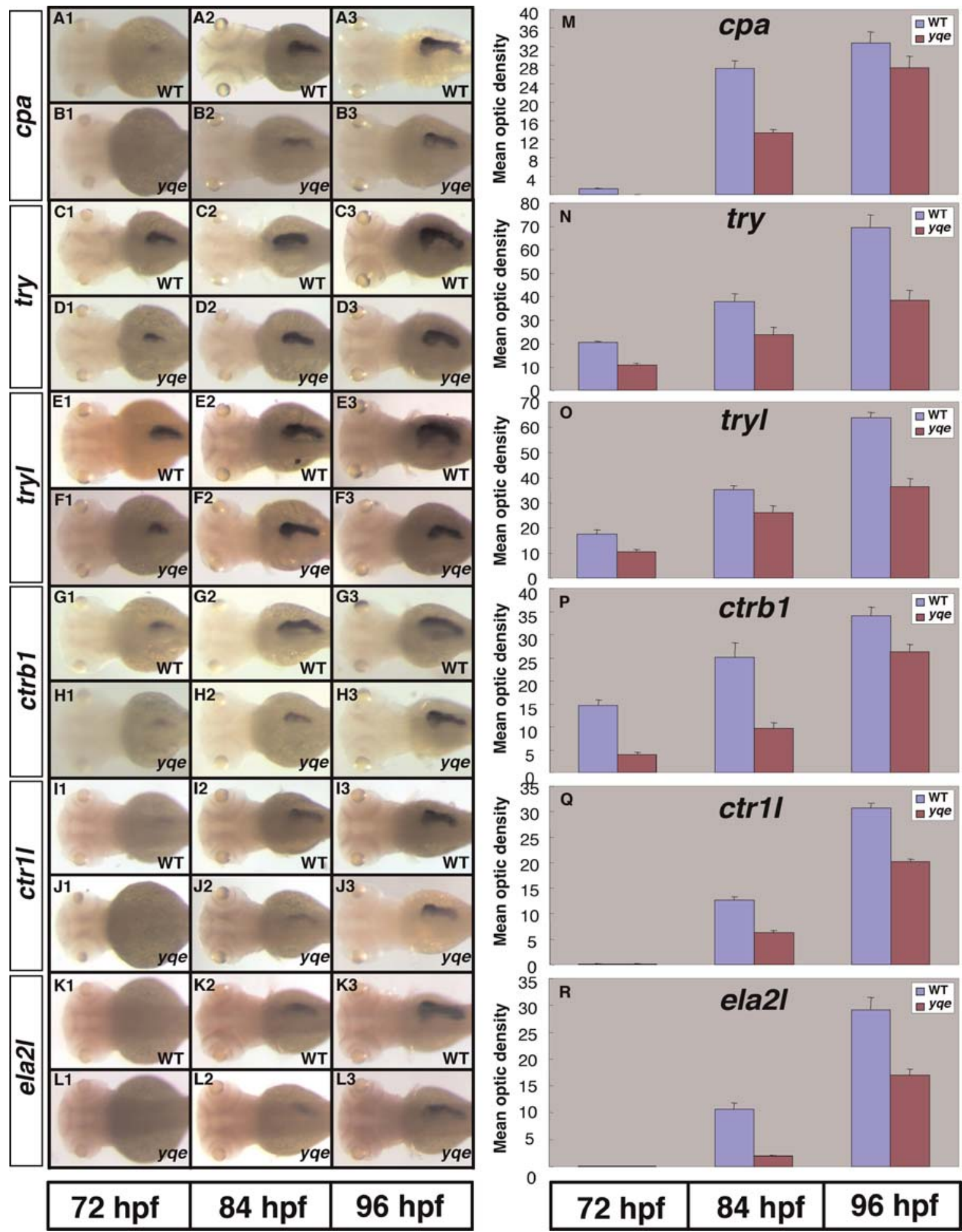

Figure 1. Downregulation of six peptidase precursor genes specifically in exocrine pancreas of the yquem/urod mutant shown by (A-L) wholemount in situ hybridization and (M-R) analyzed by ImageJ. All larvae are shown in dorsal view, anterior to the left. The six peptidase precursor genes are $(\mathrm{A}, \mathrm{B}$, and $\mathrm{M})$ cpa, $(\mathrm{C}, \mathrm{D}$, and $\mathrm{N})$ try, $(\mathrm{E}, \mathrm{F}$, and $\mathrm{O})$ tryl protein, $(\mathrm{G}, \mathrm{H}$, and $\mathrm{P})$ ctrb1, (I, J, and Q) ctrb1/ protein, and (K, L, and $\mathrm{R})$ ela2l. The mean total O.D. $=S-B$ (see Materials and Methods) in 20-50 embryos. Differences between WT and the mutant are statistically significant at all stages $(P<0.05, t$ test), except for $(\mathrm{M}) \mathrm{cpa}$ at $96 \mathrm{hpf}$, where it could result from difficult quantification of deep in situ hybridization staining as well as (Q and R) ctr1/ and ela2l at $72 \mathrm{hpf}$ where no in situ hybridization signals were detected. Error bars in M-R are standard deviation. Color figures are available in the online version of the journal. 


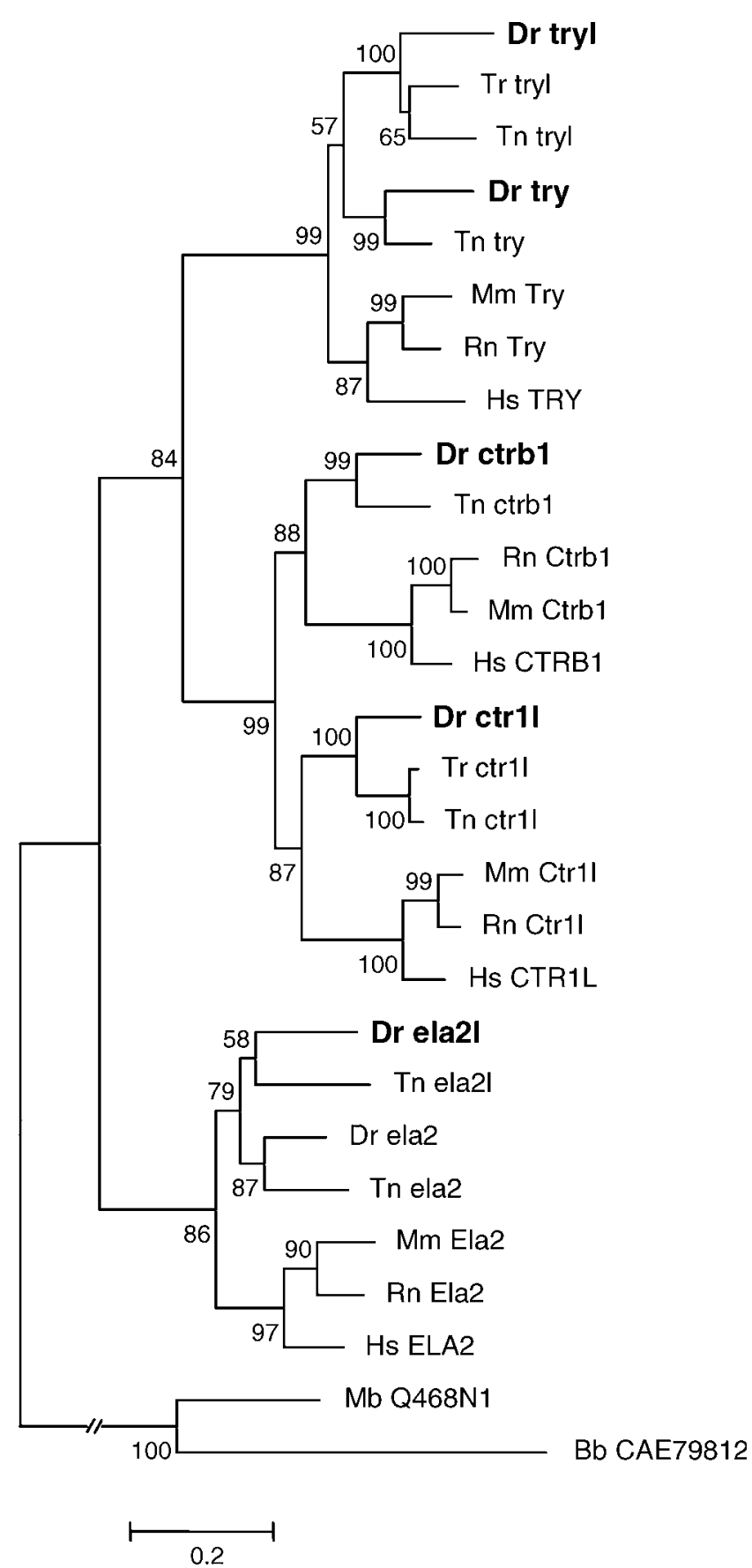

Figure 2. Phylogenetic tree using the tryp_SPc domains of serine peptidases with bacterial homologs as outgroups. The tree was constructed by the neighbor-joining method using MEGA 3.1 (17) and is a consensus derived from a heuristic search of 1000 bootstrap replicates. The numbers indicate the percentage bootstrap support. Try, trypsin precursor; tryl, trypsin-like protein; ctrb1, chymotrypsinogen B1; ctr1l, chymotrypsinogen 1-like protein; ela, elastase; $\mathrm{Dr}$, Danio rerio; Tr, Takifugu rubripes; Tn, Tetraodon nigroviridis; Hs, Homo sapiens; Rn, Rattus norvegicus; Mm, Mus musculus; Mb, Methanosarcina barkeri; Bb, Bdellovibrio bacteriovorus HD100. Mb_Q468N1 is a hypothetical protein of Methanosarcina barkeri, and Bb_CAE79812 is a putative V8-like Glu-specific endopeptidase of Bdellovibrio bacteriovorus HD100. The Genbank accession numbers of these serine peptidases are in online Supplemental Table 3. tryl are co-orthologs (20) of mammalian Try, whereas fish ela2 and ela2l are co-orthologs of mammalian Ela2 (Fig. 2), suggesting that both zebrafish try/tryl, and ela2/ela2l likely are ancient duplicates preserved after a genome-wide duplication in the teleost lineage approximately 400 million years ago (21). Further, fish ctrbl and ctrbll are orthologs of mammalian Ctrbl and Ctrll, respectively (Fig. 2).

All members of the serine peptidase SA clan have a conserved catalytic triad sequence with histidine (His), aspartate (Asp), and serine (Ser; see asterisks in online Supplemental Fig. 2). These serine peptidases function extracellularly, such as in food digestion and fibrinolysis. The preferential cleavages of trypsin (EC 3.4.21.4), chymotrypsin (EC 3.4.21.1), and elastase 2 (EC 3.4.21.71) are arginine (Arg)-unspecified amino acid (Xaa)/lysine (Lys)-Xaa, tyrosine (Tyr)-Xaa $>$ tryptophan (Trp)-Xaa $>$ phenylalanine (Phe)-Xaa $>$ leucine (Leu)-Xaa, and Leu$\mathrm{Xaa} / \mathrm{methionine}$ (Met)-Xaa/Phe-Xaa, respectively (22-24).

Identification of Three Zebrafish Novel Exocrine Pancreas-Specific Peptidase Genes. Of the six peptidase genes, try (25), ela2l (26), and cpa $(27,28)$ were previously shown to be expressed specifically in the pancreas. We now report that tryl, ctrbl, and ctrll also have pancreas-specific expression in the zebrafish (Figs. 1E, $\mathrm{G}$, and I). Phylogenetic analysis indicated zebrafish tryl is a co-ortholog of mammalian Try, whereas zebrafish ctrbl and ctrll are orthologs of mammalian Ctrbl and Ctrll, respectively (see the above and Fig. 2). The tryl gene (Genbank accession BC055625) has a predicted 726nucleotide (nt) open reading frame (ORF) and encodes a 242-amino acid (aa) protein that shares $61.5 \%$ identity to the zebrafish Try protein (see online Supplemental Table 4). The ctrbl (Genbank accession BC055574) has a predicted 789-nt ORF and encodes a 263-aa protein that shares $65.3 \%$ identity to human chymotrypsinogen B1 (29) (see online Supplemental Table 4). The ctrll (Genbank accession NM_001004582) has a 783-nt ORF and encodes a 261-aa protein that shares $60.3 \%$ identity to human chymotrypsinogen B1 (29) (see online Supplemental Table 4). All the three predicted proteins contain the tryp_SPc domains (SM00020; online Supplemental Fig. 2) and the typical serine peptidase catalytic triad (see asterisks in online Supplemental Fig. 2). Our whole-mount in situ hybridization and bioinformatic analyses suggest that these three novel genes, tryl, ctrbl, and ctrll, likely contribute to pancreatic functions.

Downregulation of the Six Peptidase Precursor Genes in sauternes/alas2. We also examined expression of the six peptidase genes in zebrafish mutant saulalas 2 (30), wherein a missense mutation (V249D) in the gene encoding the first and rate-liming erythroid-specific $\delta$ isoform of ALAS2 (EC 2.3.1.375) in heme biosynthesis results in microcystic and hypochromic anemia (10). Whole-mount in situ hybridization showed downregulation of these six peptidase precursor genes in the saulalas 2 mutant ( $P<0.05$, ANOVA; see Fig. 4). Because ALAS2 

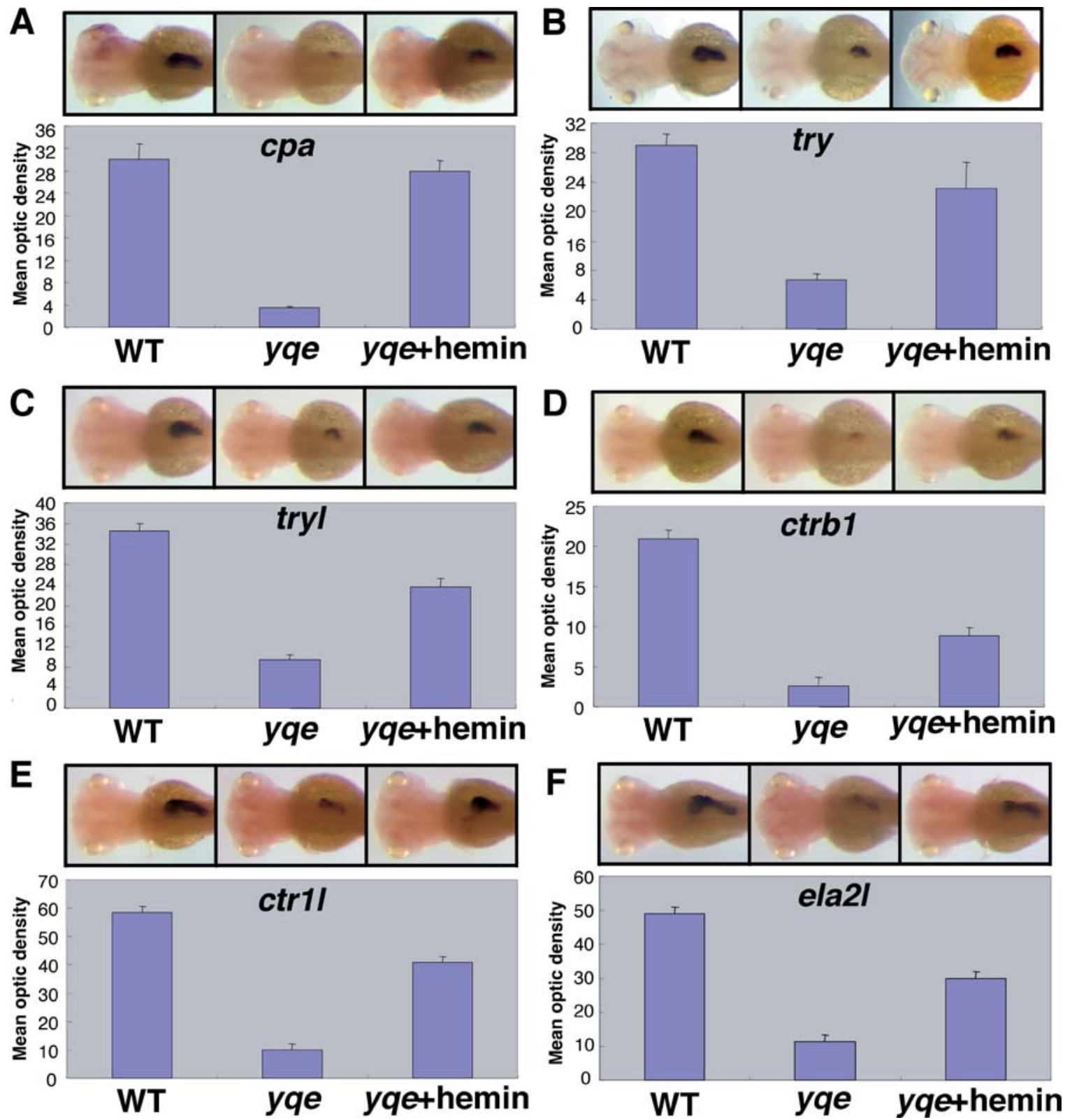

Figure 3. Rescue the expression of the six peptidase precursor genes in yquem/urod (-I-) by hemin treatment. All larvae are shown in dorsal view, anterior to the left. Larvae are $74 \mathrm{hpf}$ in (A) cpa, (B) try, (C) tryl, and (D) ctrb1, and $97 \mathrm{hpf}$ in (E) ctr1/ and (F) ela2l. The O.D. of staining (S) and the neighboring background $(B)$ were measured by ImageJ. The mean total O.D. $=S-B$ (see Materials and Methods) in $20-50$ embryos. Error bars are standard deviation. (A-F) Differences of signal intensities between hemin-treated and untreated larvae are statistically significant $(P<0.001$, ANOVA). Color figures are available in the online version of the journal.

(the first enzyme) and UROD (the fifth enzyme) are in the same heme biosynthetic pathway, our results of downregulation of the six zymogens in both yquem/urod and saul alas 2 strongly suggest that heme is required for expression of these zymogens in zebrafish.

Downregulation of ptf1a in the Exocrine Pancreas of Zebrafish yquem/urod and sauternes/ alas2. To investigate the molecular genetic mechanisms underlying heme regulation of exocrine zymogens, we examined the expression of pancreas transcription factor $1 \alpha(p t f l a)$, which encodes a pancreas-specific basic helix- loop-helix (bHLH) transcription factor. PTF1A, the $48-\mathrm{kDa}$ DNA-binding subunit of the heterotrimeric pancreas transcription factor-1 (PTF1) complex, is required for activating digestive zymogens (31) and zebrafish exocrine acinar cell differentiation and development (32). Whole-mount in situ hybridization showed that ptfla is downregulated in both yquem/urod and sauternes/alas 2 mutant larvae $(P<0.05$, ANOVA; see Fig. 5).

Rescue of Expression of ptf1a and the Six Peptidase Precursor Genes in yquem/urod and sauternes/alas2 by Hemin Treatment. To determine 

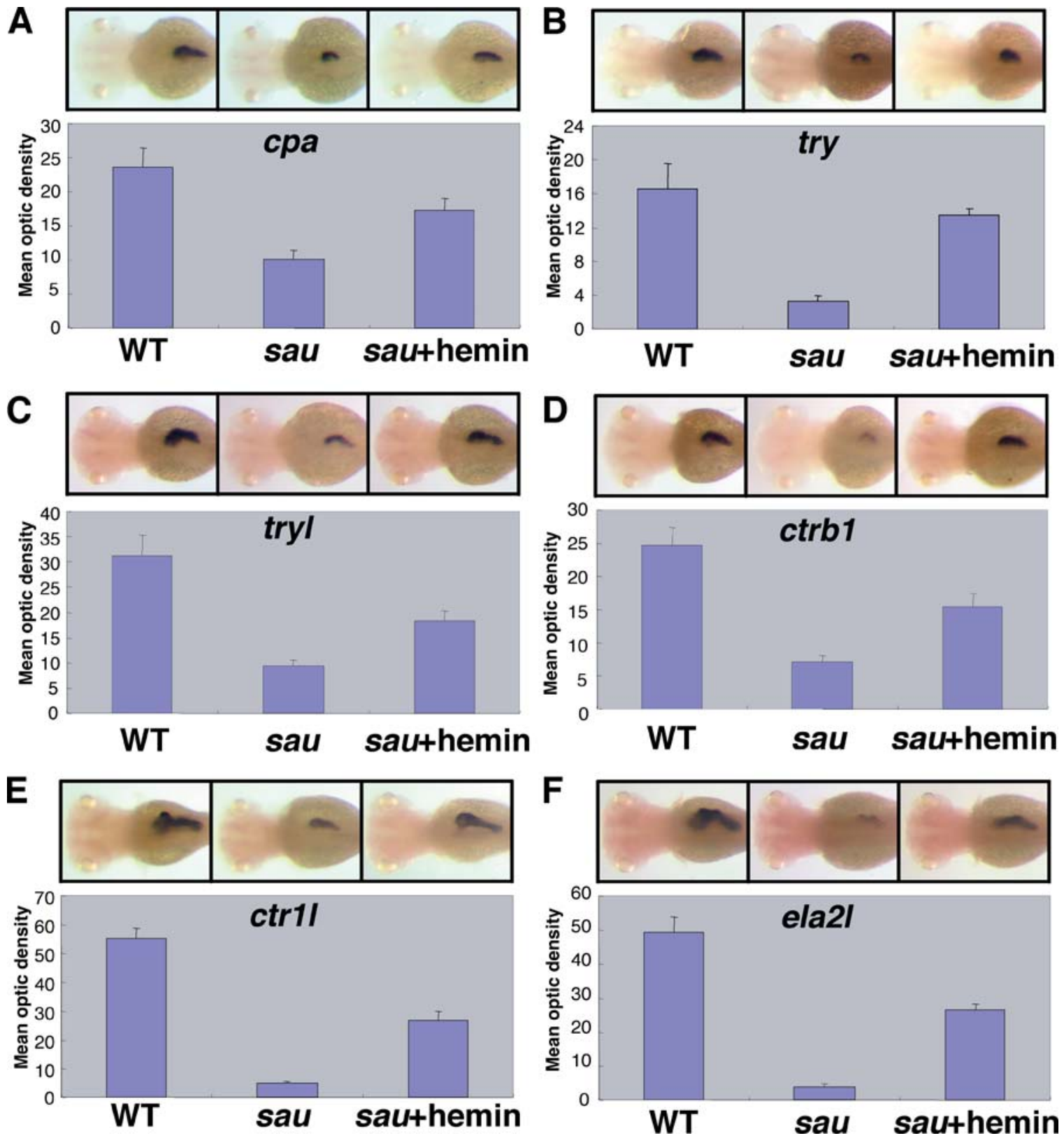

Figure 4. Downregulation of the six peptidase precursor genes in sau/alas2 (-/-) and rescue of their downregulated expression in sau/alas2 (-I $-)$ by hemin treatment. All larvae are shown in dorsal view, anterior to the left. Larvae are $74 \mathrm{hpf}$ in (A) cpa, (B) try, (C) tryl, and (D) ctrb1, and 97 hpf in $(E)$ ctr1l and $(F)$ ela2l. The O.D. of staining $(S)$ and the neighboring background $(B)$ were measured by ImageJ. The mean total O.D. $=S-$ $B$ (see Materials and Methods) 10-30 embryos. Error bars are standard deviation. (A-F) Differences of signal intensities between hemin-treated and untreated larvae are statistically significant $(P<0.001$, ANOVA), except for $(A)$ cpa $(P<0.05$, ANOVA). Color figures are available in the online version of the journal.

whether heme regulates zebrafish exocrine zymogens, the yquem/urod and sauternes/alas2 mutant larvae were treated with $1 \mu M$ hemin for $1 \mathrm{hr}$ and then fixed for in situ hybridization experiments. Remarkably, the expression of ptfla and the six peptidase precursor genes was rescued in hemin-treated yquem/urod and sauternes/alas 2 mutant larvae $(P<0.05$, ANOVA; see Figs. $3-5)$. We did not observe significant differences in the exocrine pancreatic expression domains for all six zymogens and ptfla between hemin-treated WT and untreated WT larvae, nor did we observe any significant differences for them between vehicle solution-treated and untreated yquem/urod and sauternes/ alas 2 mutant larvae (data not shown).

\section{Discussion}

Our study now provides evidence that heme plays an important role in regulating zebrafish exocrine zymogens. Heme, the prosthetic moiety for a variety of proteins that have critical roles in oxygen transportation, mitochondrial function, and signal transduction, seems to have evolved to 

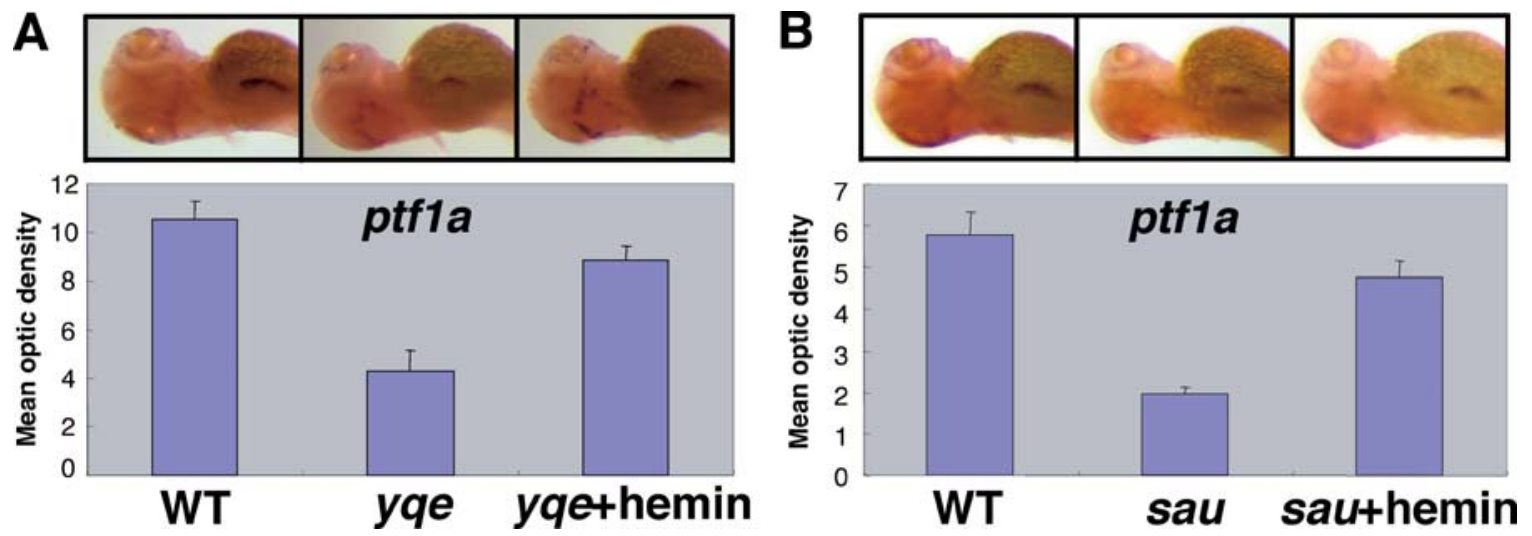

Figure 5. Downregulation of ptf1a in both yquem/urod (-/-) and sau/alas2 (-/-) and rescue of its downregulated expression in both yquem/urod $(-I-)$ and sau/alas2 $(-I-)$ by hemin treatment. All larvae are shown as left dorsal oblique view, anterior to the left. Downregulation of ptf1a was also observed in the (panel A) yquem/urod (-I) mutant and the (panel B) sau/alas2 (-I-) mutant and its downregulated expression is rescued by hemin treatment. Larvae are $74 \mathrm{hpf}$ in panels $A$ and B. The O.D. of staining $(S)$ and the neighboring background $(B)$ were measured by ImageJ. The mean total O.D. $=S-B$ (see Materials and Methods) 30-50 embryos. Error bars are standard deviation. Differences of signal intensities between hemin-treated and untreated larvae in A and B are statistically significant $(P<0.05$, ANOVA). Color figures are available in the online version of the journal.

have other biological functions in addition to its widely known roles in biosynthesis of hemoglobin, cytochromes, and nitric oxide synthase. In this regard, heme was recently found to differentially modulate expression of $m P e r l$ and $m P e r 2$ and thereby regulate the circadian clock by controlling BMAL1:NPAS2-mediated transcription activities (33). In addition, heme is required for differentiation of mammalian erythroid, hepatic, and nervous cells (2-5), and it also suppresses the apoptosis of human neutrophils (6), PC12 neurons (7), and HeLa cells (8), whereas hemin activates heme oxygenase-1 (Ho-1)-mediated macrophages recruitment to the pancreas and hence prevents from acute pancreatitis in mouse (34).

Our microarray analysis and in situ hybridization experiments consistently showed that these six exocrine peptidase precursor genes are downregulated in yquem/urod zebrafish, even though expression levels between yquem/ urod and WT zebrafish determined by the two methods may not be the same for some of these six genes at specific developmental stages (Fig. 1 and Table 1). This is likely a result of the differences in detection sensitivity of the two methods. Whereas microarray analysis appears to measure the whole expression level of a gene at a specific developmental stage, the in situ hybridization-based Image $\mathrm{J}$ analysis allows for detection of a relative expression level of the gene at that stage, in particular the expression of the gene in the deep cells (for instance, inside the exocrine pancreas) may not be estimated precisely. Even so, the independent in situ hybridization experiments clearly corroborated the microarray results for most of the stages examined (Fig. 1 and Table 1).

In addition to activating transcription of exocrine peptidase precursor genes (31), PTF1A also is required for zebrafish exocrine acinar cell differentiation and development (32). Thus, it is possible that exocrine pancreatic development is delayed in yquem/urod, and sauternes/alas2 mutant larvae resulted from downregulation of ptfla, which should also contribute to the observed downregulation of these exocrine zymogens. Further, hemin treatment also induces Ho-1, one of the three heme oxygenase enzymes that catalyze the degradation of heme (34-36). It is also possible that Ho-1 will in turn inhibit heme-mediated transcription of these exocrine zymogens by degrading heme per se. In fact, the likelihood of the exocrine pancreatic developmental delay as well as the induction of Ho-1 may have resulted in partial rescue of zymogen transcription by hemin treatment (Figs. 3 and 4). Though not completely rescued, the rapid response to hemin treatment by these exocrine zymogens strongly suggests that heme likely regulates their transcription.

Mammalian studies have implicated important roles for PTF1A in the development of the exocrine pancreas (37). As a member of the bHLH transcription factor family, PTF1A activates the genes by binding the E-box in the 5' flanking region of the controlled genes $(31,38-40)$. Interestingly, all six zymogens possess multiple E-boxes (CANNTG) in the 5' flanking regions (approximately 6000 nt upstream of the transcription site; Table 3), supporting the idea that PTF1A regulates these six zymogens in zebrafish.

Importantly, several heme-responsive transcription factors recently were revealed, such as the iron regulatory regulator (Irr) in the bacterium Bradyrhizobium japonicum (41), the heme activator protein (Hap1) in the yeast Saccharomyces cerevisiae $(5,42)$, and the transcriptional repressor Bach1 in mammals $(43,44)$. All the hemeregulated proteins share cysteine- and proline-containing heme regulatory motifs (HRMs) that heme directly binds to (45). A database search using mammalian homologs identified zebrafish bach2 (Genbank accession XP_682933), with the predicted zebrafish BACH2 protein containing four heme-binding HRMs and a DNA-binding basic leucine zipper (bZip) domain (SM00338) (data not 
shown). It is tempting to imagine that zebrafish hemeresponsive proteins, such as $\mathrm{BACH} 2$, may be a missing link through which heme exerts its regulatory role on transcription of ptfla, and then, the PTF1A protein regulates these six zymogens in zebrafish. Alternatively, BACH2 or other zebrafish heme-responsive proteins may directly regulate these six zymogens in zebrafish. On the other hand, Ho-1 induced by hemin treatment catalyzes the breakdown of heme into biliverdin, carbon monoxide (CO) and iron (34-36). Biliverdin is subsequently converted into bilirubin by biliverdin reductase $(35,36)$. All the three heme degradation products, bilirubin, $\mathrm{CO}$ and iron, appear to have regulatory or signaling roles in various physiological and cellular processes (35). Further investigation is needed to examine these competing hypotheses concerning how heme and the heme-responsive proteins regulate the ptfla expression as well as whether the heme-responsive proteins, Ho- 1 , and the three heme degradation products directly regulate zymogens.

Hemin, a heme substrate analog, has been used clinically to treat porphyria patients to alleviate the acute episodic pains, although the mechanism underlying this treatment is still elusive (46-48). Because molecular genetic pathways underlying many zebrafish and human biochemical, developmental, and physiological processes are highly conserved $(49,50)$, it is tempting to speculate that the acute episodic abdominal pains associated with nausea and vomiting inflicted upon porphyria patients (48) are caused by underproduction of exocrine zymogens resulting from heme deficiency, and hemin treatment alleviate these pains (46-48) by restoring zymogen production levels. Our study suggests that patients with porphyria and a heme deficiency, who also have exocrine pancreatic problems caused by symptomatic underproduction of zymogens, would benefit by hemin treatment (46-48) as it would help increase zymogen production levels.

In summary, our results indicated that heme deficiency results in underproduction of exocrine zymogens and heme regulates exocrine zymogens in zebrafish. These findings add to a growing body of knowledge regarding heme deficiency pathogenesis and should enhance our ability to diagnose and treat human patients with porphyria or pancreatic diseases.

We thank George Martin for maintaining our zebrafish facility; Michael Centola, Mark Barton Frank, and Yuhong Tang for performing the microarray analysis; Len Zon for providing the sauternes $\left(\right.$ sau $\left.^{t b 223}\right)$ line; Bruce Roe, Jonathan Wren, and Yi Zhou for helpful comments on the manuscript; and members of our laboratory for constructive discussion.

1. Mense SM, Zhang L. Heme: a versatile signaling molecule controlling the activities of diverse regulators ranging from transcription factors to MAP kinases. Cell Res 16:681-692, 2006.

2. Padmanaban G, Venkateswar V, Rangarajan P. Haem as a multifunctional regulator. Trends Biochem Sci 14:492-496, 1989.
3. Sassa S, Nagai T. The role of heme in gene expression. Int J Hematol 63:167-178, 1996.

4. Ponka P. Cell biology of heme. Am J Med Sci 318:241-256, 1999.

5. Zhang L, Hach A. Molecular mechanism of heme signaling in yeast: the transcriptional activator Hap1 serves as the key mediator. Cell Mol Life Sci 56:415-426, 1999.

6. Arruda MA, Rossi AG, de Freitas MS, Barja-Fidalgo C, Graca-Souza AV. Heme inhibits human neutrophil apoptosis: involvement of phosphoinositide 3-kinase, MAPK, and NF-\{kappa\}B. J Immunol 173:2023-2030, 2004.

7. Sengupta A, Hon T, Zhang L. Heme deficiency suppresses the expression of key neuronal genes and causes neuronal cell death. Brain Res Mol Brain Res 137:23-30, 2005.

8. Ye W, Zhang L. Heme controls the expression of cell cycle regulators and cell growth in HeLa cells. Biochem Biophys Res Commun 315: 546-554, 2004.

9. Wang H, Long Q, Marty S, Sassa S, Lin S. A zebrafish model for hepatoerythropoietic porphyria. Nat Genet 20:239-243, 1998.

10. Brownlie A, Donovan A, Pratt S, Paw B, Oates A, Brugnara C, Witkowska H, Sassa S, Zon L. Positional cloning of the zebrafish sauternes gene: a model for congenital sideroblastic anaemia. Nat Genet 20:244-250, 1998.

11. Childs S, Weinstein BM, Mohideen MA, Donohue S, Bonkovsky H, Fishman MC. Zebrafish dracula encodes ferrochelatase and its mutation provides a model for erythropoietic protoporphyria. Curr Biol 10:10011004, 2000.

12. Sakamoto D, Kudo H, Inohaya K, Yokoi H, Narita T, Naruse K, Mitani H, Araki K, Shima A, Ishikawa Y, Imai Y, Kudo A. A mutation in the gene for delta-aminolevulinic acid dehydratase (ALAD) causes hypochromic anemia in the medaka, Oryzias latipes. Mech Dev 121: 747-752, 2004.

13. Westerfield M. The Zebrafish Book: Guide for the laboratory use of zebrafish (Danio rerio). Eugene, OR: University of Oregon Press, 1995.

14. Dozmorov I, Centola M. An associative analysis of gene expression array data. Bioinformatics 19:204-211, 2003.

15. Thompson J, Gibson T, Plewniak F, Jeanmougin F, Higgins D. The ClustalX windows interface: flexible strategies for multiple sequence alignment aided by quality analysis tools. Nucleic Acids Res 24:48764882, 1997.

16. Hall TA. BioEdit: a user-friendly biological sequence alignment editor and analysis program for Windows 95/98/NT. Nucl Acids Symp Ser 41:95-98, 1999.

17. Kumar S, Tamura K, Nei M. MEGA3: integrated software for molecular evolutionary genetics analysis and sequence alignment. Brief Bioinform 5:150-163, 2004.

18. Freedman ML, Geraghty M, Rosman J. Hemin control of globin synthesis: isolation of a hemin-reversible translational repressor from human mature erythrocytes. J Biol Chem 249:7290-7294, 1974.

19. Petra PH. Bovine procarboxypeptidase and carboxypeptidase A. Methods Enzymol 19:460-503, 1970.

20. Sonnhammer EL, Koonin EV. Orthology, paralogy and proposed classification for paralog subtypes. Trends Genet 18:619-620, 2002.

21. Amores A, Force A, Yan YL, Joly L, Amemiya C, Fritz A, Ho RK, Langeland J, Prince V, Wang YL, Westerfield M, Ekker M, Postlethwait JH. Zebrafish hox clusters and vertebrate genome evolution. Science 282:1711-1714, 1998.

22. Chopek M, Girma J, Fujikawa K, Davie E, Titani K. Human von Willebrand factor: a multivalent protein composed of identical subunits. Biochemistry 25:3146-3155, 1986.

23. Fletcher T, Shen W, Largman C. Primary structure of human pancreatic elastase 2 determined by sequence analysis of the cloned mRNA. Biochemistry 26:7256-7261, 1987.

24. Kawashima I, Tani T, Shimoda K, Takiguchi Y. Characterization of 
pancreatic elastase II cDNAs: two elastase II mRNAs are expressed in human pancreas. DNA 6:163-172, 1987.

25. Biemar F, Argenton F, Schmidtke R, Epperlein S, Peers B, Driever W. Pancreas development in zebrafish: early dispersed appearance of endocrine hormone expressing cells and their convergence to form the definitive islet. Dev Biol 230:189-203, 2001.

26. Mudumana S, Wan H, Singh M, Korzh V, Gong Z. Expression analyses of zebrafish transferrin, ifabp, and elastaseB mRNAs as differentiation markers for the three major endodermal organs: liver, intestine, and exocrine pancreas. Dev Dyn 230:165-173, 2004.

27. dilorio P, Moss J, Sbrogna J, Karlstrom R, Moss L. Sonic hedgehog is required early in pancreatic islet development. Dev Biol 244:75-84, 2002.

28. Kim H, Schleiffarth J, Jessurun J, Sumanas S, Petryk A, Lin S, Ekker S. Wnt5 signaling in vertebrate pancreas development. BMC Biol 3:23, 2005 .

29. Hou D, Ozawa K, Tomita N, Maeda Y, Hashiguchi T, Yokoyama K, Soeda E. Genomic cloning and partial characterization of human chymotrypsinogen gene. Jpn J Hum Genet 38:371-380, 1993.

30. Ransom D, Haffter P, Odenthal J, Brownlie A, Vogelsang E, Kelsh R, Brand M, van Eeden F, Furutani-Seiki M, Granato M, Hammerschmidt M, Heisenberg C, Jiang Y, Kane D, Mullins M, Nusslein-Volhard C. Characterization of zebrafish mutants with defects in embryonic hematopoiesis. Development 123:311-319, 1996.

31. Rose SD, Swift GH, Peyton MJ, Hammer RE, MacDonald RJ. The role of PTF1-P48 in pancreatic acinar gene expression. J Biol Chem 276: 44018-44026, 2001.

32. Lin J, Biankin A, Horb M, Ghosh B, Prasad N, Yee N, Pack M, Leach $\mathrm{S}$. Differential requirement for ptf1a in endocrine and exocrine lineages of developing zebrafish pancreas. Dev Biol 274:491-503, 2004.

33. Kaasik K, Lee C. Reciprocal regulation of haem biosynthesis and the circadian clock in mammals. Nature 430:467-471, 2004.

34. Nakamichi I, Habtezion A, Zhong B, Contag CH, Butcher EC, Omary MB. Hemin-activated macrophages home to the pancreas and protect from acute pancreatitis via heme oxygenase-1 induction. J Clin Invest 115:3007-3014, 2005.

35. Galbraith R. Heme oxygenase: who needs it? Proc Soc Exp Biol Med 222:299-305, 1999.

36. Farombi EO, Surh YJ. Heme oxygenase-1 as a potential therapeutic target for hepatoprotection. J Biochem Mol Biol 39:479-491, 2006.

37. Kawaguchi Y, Cooper B, Gannon M, Ray M, MacDonald R, Wright C.
The role of the transcriptional regulator Ptf1a in converting intestinal to pancreatic progenitors. Nat Genet 32:128-134, 2002.

38. Cockell M, Stevenson BJ, Strubin M, Hagenbuchle O, Wellauer PK. Identification of a cell-specific DNA-binding activity that interacts with a transcriptional activator of genes expressed in the acinar pancreas. Mol Cell Biol 9:2464-2476, 1989.

39. Krapp A, Knofler M, Frutiger S, Hughes GJ, Hagenbuchle O, Wellauer PK. The p48 DNA-binding subunit of transcription factor PTF1 is a new exocrine pancreas-specific basic helix-loop-helix protein. EMBO J 15:4317-4329, 1996.

40. Sellick GS, Barker KT, Stolte-Dijkstra I, Fleischmann C, Coleman RJ, Garrett C, Gloyn AL, Edghill EL, Hattersley AT, Wellauer PK, Goodwin G, Houlston RS. Mutations in PTF1A cause pancreatic and cerebellar agenesis. Nat Genet 36:1301-1305, 2004.

41. Qi Z, Hamza I, O'Brian MR. Heme is an effector molecule for irondependent degradation of the bacterial iron response regulator (Irr) protein. Proc Natl Acad Sci U S A 96:13056-13061, 1999.

42. Zitomer RS, Lowry CV. Regulation of gene expression by oxygen in Saccharomyces cerevisiae. Microbiol Mol Biol Rev 56:1-11, 1992.

43. Igarashi $\mathrm{K}$, Itoh $\mathrm{K}$, Hayashi $\mathrm{N}$, Nishizawa $\mathrm{M}$, Yamamoto $\mathrm{M}$. Conditional expression of the ubiquitous transcription factor mafk induces erythroleukemia cell differentiation. Proc Natl Acad Sci U S A 92:7445-7449, 1995.

44. Ishikawa M, Numazawa S, Yoshida T. Redox regulation of the transcriptional repressor Bach1. Free Radic Biol Med 38:1344-1352, 2005

45. Zhang L, Guarente L. Heme binds to a short sequence that serves a regulatory function in diverse proteins. EMBO J 14:313-320, 1995.

46. Bickers DR. Treatment of the porphyrias: mechanisms of action. J Invest Dermatol 77:107-113, 1981.

47. Pierach CA. Hematin therapy for the porphyric attack. Semin Liver Dis 2:125-131, 1982.

48. Anderson KE, Bloomer JR, Bonkovsky HL, Kushner JP, Pierach CA, Pimstone NR, Desnick RJ. Recommendations for the diagnosis and treatment of the acute porphyrias. Ann Intern Med 142:439-450, 2005.

49. Barut BA, Zon LI. Realizing the potential of zebrafish as a model for human disease. Physiol Genomics 2:49-51, 2000.

50. Driever W, Fishman MC. The zebrafish: heritable disorders in transparent embryos. J Clin Invest 97:1788-1794, 1996. 